\title{
A Double-Hurdle model of urban green areas valuation: Dealing with zero responses
}

\author{
Salvador del Saz-Salazar ${ }^{\mathrm{a}, *}$, Pau Rausell-Köster ${ }^{\mathrm{b}}$ \\ ${ }^{a}$ Departamento de Estructura Económica, Universitat de València, Avda. dels Tarongers s/n, 46022 Valencia, Spain \\ ${ }^{\mathrm{b}}$ Departamento de Economía Aplicada, Universitat deValència, Avda. dels Tarongers s/n, 46022 Valencia, Spain
}

Received 12 January 2007; received in revised form 18 July 2007; accepted 23 August 2007

\begin{abstract}
Due to the widespread support for public parks and open spaces in urban areas, there is an increasing need to analyse the social benefits that are generated by such amenities. The city of Valencia (Spain) has a large park that can be considered its green backbone due to its transversal layout running along 9 of the 19 districts into which the city is divided. A contingent valuation survey was therefore conducted in order to obtain the non-market benefits derived from the use of this park by the inhabitants of Valencia. In addition, to deal with the large number of zero responses obtained, a Double-Hurdle model was applied. The results show that this model is more appropriate than other, simpler approaches. They also show that willingness to pay is positively related with the respondent's income and education, as was expected. Another interesting finding is that willingness to pay is also affected by the section of the park in which the interview was conducted. The information gathered form this study is of interest to decision-making with regard environmental issues.
\end{abstract}

(C) 2007 Elsevier B.V. All rights reserved.

Keywords: Urban green areas; Contingent valuation; Double-Hurdle model; Decision-making

\section{Introduction}

With an increasing population living in cities and metropolitan areas - according to UNFPA (2005) in Spain a 77\% of the population lives in urban areas while in Western Europe this figure is $81 \%$ - there is strong and widespread support for public parks and open spaces due to the different ways they enhance the quality of life in areas dominated by asphalt, concrete and noise. Several reasons support this view. First, city parks and open spaces improve physical and psychological health by encouraging people to take regular exercise. Chiesura (2004) found out that people perceive the feelings and emotions evoked in the parks as very important factors in their sense of well-being. The quietness of an urban environment free of noise was assessed by Barreiro et al. (2005). Second, green space in urban areas provides substantial environmental benefits. For example, trees can play an important role in reducing air pollution, they also help to keep cities cooler and they are the most effective and cheap-

\footnotetext{
* Corresponding author.

E-mail address: Salvador.Saz@uv.es (S.d. Saz-Salazar).
}

est way of controlling stormwater runoff (Sherer, 2006). Third, urban parks have an important aesthetic value in an environment designed around the automobile. According to Wilson's (1993) biophilia hypothesis people have an innately preference for natural over urban landscapes, especially if the latter lack vegetation and water. Fourth, urban parks are also important for wildlife because they create potential habitats for birds and other animals. Finally, there is a new view of urban parks as valuable contributors to wider urban objectives such as job opportunities, youth development and community building (Walker, 2004).

The estimation of the numerous benefits that urban parks provide for society is a difficult task because such benefits are of a non-market nature. However, the absence of a market does not necessarily imply the absence of value, since these benefits allegedly have a high social value through their contribution to the improvement of individual welfare. Economists have traditionally addressed this valuation problem by adopting two approaches. Firstly, by looking for clues in related property markets, as in the case of the hedonic pricing method (Rosen, 1974; Freeman, 1993) and other revealed preferences techniques-travel cost method and averting behaviour. In fact, in the literature there are numerous examples of the effects

0169-2046/\$ - see front matter @ 2007 Elsevier B.V. All rights reserved. doi:10.1016/j.landurbplan.2007.08.008 
of urban parks and open spaces on residential property values (see, for example, Jim and Chen, 2006a; Mansfield et al., 2005; Hobden et al., 2004; Bengochea, 2003; Tajima, 2003; Geoghegan, 2002; Din et al., 2001; Bolitzer and Netusil, 2000; Luttik, 2000; Tyrväinen, 1997; Tyrväinen and Meittinen, 2000; Powe et al., 1995; Palmquist, 1992). However, this traditional approach typically capture only the proximal residential benefits of urban parks (Loomis et al., 2004), ignoring other potential benefits such as those described earlier. It would therefore seem more appropriate to use a second group of techniques called stated preferences methods which, in principle, allow the researcher to capture all the range of benefits arising from urban parks. Among this second group of techniques, the contingent valuation method (CVM) (Mitchell and Carson, 1989) is the most widely used methodology to value non-market and public goods. As Smith (2006) points out, the CVM is a technique that has been developed in the last 50 years. This technique involves the direct questioning of people to elicit their willingness to pay (WTP) for a particular good or service that implies an improvement in their well-being. The attraction of this methodology is that it facilitates the construction of a market in which the researcher can observe an economic decision directly related to the good in question (Carson, 1991). The number of papers that have applied the CVM to this valuation topic is still small in comparison to the revealed preference techniques (see, for example, Saz and García-Menéndez, 2007; Jim and Chen, 2006b; Damigos and Kaliampakos, 2003; Willis, 2003; Breffel et al., 1998; Tyrväinen and Väänänen, 1998).

In this paper, we apply the CVM to estimate the social benefits arising from the use of an urban park in the city of Valencia (Spain). This park, which covers more than 117 ha and is located in the dry bed of the Turia River, can be considered the green backbone of the city. The information gathered from this study is of interest in decision-making on environmental issues. However, environmental issues are so complex in nature that their study must be addressed from an interdisciplinary point of view, so CVM, like any other methodology, has its limitations (Hausman, 1993; Diamond and Hausman, 1993, 1994; Diamond, 1996) and on its own cannot provide the definitive answer to any major policy question (Carson, 1998).

Apart from the estimation of the social benefits, this study also deals with the issue of zero responses by applying a DoubleHurdle model (Cragg, 1971). When an open-ended question is used in the valuation scenario, this model distinguishes between factors affecting whether or not respondents are in the market for this public asset, and factors that affect the stated amount that they are willing to pay. The results obtained show that this approach is more appropriate than other approaches, e.g. the Tobit model, that do not explicitly account for these two decisions taken by the respondent facing a CVM interview. In order to validate our results from a theoretical point of view, attention is also paid to the sign and signification of the variables that explain the variation in stated bid values.

The article first describes the public asset valued. It then presents the survey process, the empirical models chosen and the main results obtained. Finally, conclusions and policy recommendations follow.

\section{Case study: "El Jardín del Túria"}

Valencia, with a population of 807,396 inhabitants, is the third most populated city in Spain. The River Túria used to cross the city from the west to the east on its way to Mediterranean Sea. However, after the tragic flooding of 1957, the course of the river was altered and with the passage of time the dry bed was converted (little by little and with a lack of planning until the 1980s) into an urban park known as "El Jardín del Túria". This park covers an area of $1,173,270 \mathrm{~m}^{2}$, making up $27.17 \%$ of the total green areas of the city. However, despite the provision of greenbelts, Valencia with an average of $5.41 \mathrm{~m}^{2}$ of green areas per inhabitant, still falls considerably short of the general target established by the World Health Organisation of a minimum of $9 \mathrm{~m}^{2}$ of green space per city dweller.

"El Jardín del Turía" can be considered the green backbone of the city due to its transversal layout from west to east and the fact that it is adjacent to 9 of the 19 districts into which the city is divided (see Fig. 1). Along this transversal layout the ten different sections that make up the park share some common morphology derived from the original course of the river. Nevertheless, these sections form a series of consecutive parks that differ both in their landscape form and in the facilities and uses that they offer the visitor.

The vast majority of people that use the park come from the city of Valencia itself since the park is primarily a space for recreation and relaxation for the inhabitants of the adjoining areas trying to escape from noise and pollution. Non-resident users account for $13.7 \%$ of visitors and are mainly to be found in the area of the park that has been given over to "La Ciudad de las Artes y de las Ciencias", now an international tourist attraction for the city due to the different museums it houses.

According to our data, the park is mainly used for walking, for sports as football, jogging and cycling, and as a meeting place for friends. With regard to the duration and frequency of visits, a $78 \%$ of the visitors stated that their visits last longer than $40 \mathrm{~min}$, while a $37.5 \%$ stated that they visit the park more than five times per month. Apart from this, the park is also used by the local authorities as a place for public events such as live music concerts, firework displays and other public performances and exhibitions. However, it is also important to remember that given its transversal layout and extensive nature, the park is a valuable contributor to community building strengthening the ties among neighbourhoods of different socio-economic status.

\section{Survey design}

After the pre-test stages, the final survey was fielded in spring 2005. Some of the guidelines suggested by the NOAA panel (Arrow et al., 1993) were followed during the different stages of the survey process. In particular, special attention was paid to the pre-test of the questionnaire, the reminder of alternative expenditure possibilities that compete for the respondent's resources and the inclusion of a variety of other questions that later help to interpret the responses to the primary valuation question. However, as a consequence of funding restraints we used a direct 


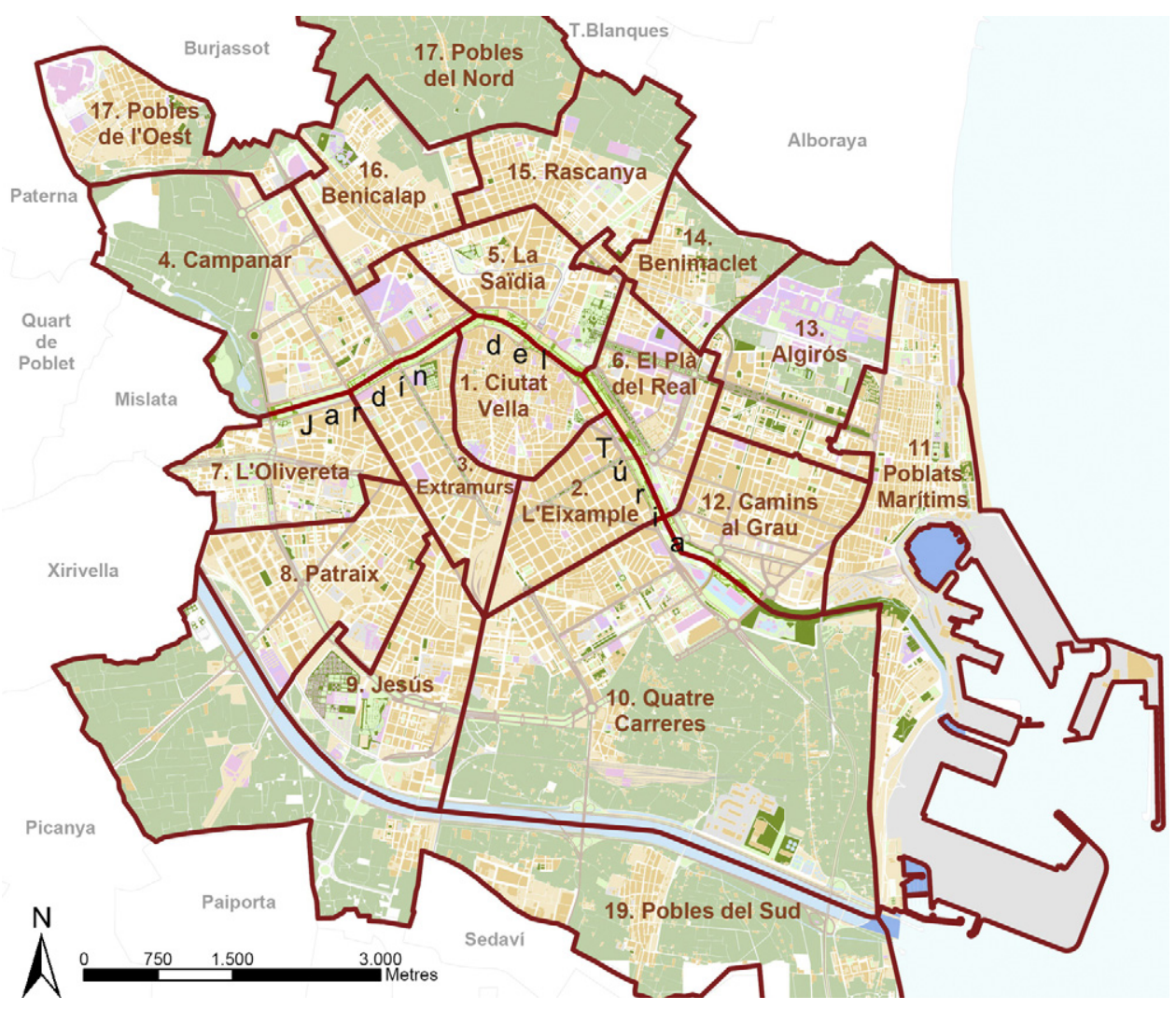

Fig. 1. Location of the Jardín del Túria and the different districts of the city of Valencia.

open-ended question instead a close-ended question that would have required a higher sampling effort in order to be statistically efficient. As Mitchell and Carson (1989) point out, some researchers advocate the use of the discrete choice or closeended elicitation format because they believe that this technique makes the task of answering a contingent valuation question easier. Nevertheless, if it were not for this methodological consideration, contingent valuation researchers would always prefer to obtain the respondent's maximum WTP amount because this gives much more information about the respondent's value for the public good in question, and therefore allows for the use of relatively straightforward statistical techniques.

A total of 1480 face-to-face interviews were conducted by more than ten well trained interviewers at the different sections of the park following random routes (see Table 1); this method was consider to have advantages over other delivery modes for the questionnaire (for example by telephone or mail). Mitchell and Carson (1995) argue strongly in favour of personal interviews because the greater control possible in the interview situation is argued to be a significant advantage over less controllable mail surveys. The survey was carried out by a market research consultancy and a stratified sample was elaborated by establishing quotas according to the demographic structure of the population, so the main sample parameters (income, age, education, gender, etc.) closely resemble those of the entire population of the city. The weight assigned to each section in the final sample was calculated by considering both the population of the surrounding districts of the city as the ease of access and the kind of services that each section offers to the visitors (e.g. the section called 'La Ciudad de las Artes' receives a larger number of visitors given that it is home to several museums and exhibition facilities).

The questionnaire was divided into three sections. To those who are not familiar with Contingent Valuation scenario design a very interesting and introductory paper that they should not to miss is Whitehead (2006). The first contained attitudinal questions in order to prepare the respondent for the answering of some more difficult questions later. Therefore, this section of the questionnaire mainly asked people about their behaviour, thus providing evidence of the different uses of the park by the visitors (e.g. duration and frequency of visits; type of activity developed, etc.).

Table 1

Number of interviews carried out by section of the park

\begin{tabular}{lcc}
\hline Section & No interviews & Weight $(\%)$ \\
\hline Parque de cabecera & 121 & 8.18 \\
Campanar & 22 & 1.49 \\
Atletismo & 71 & 4.80 \\
Bosque Mediterráneo & 113 & 7.64 \\
Serranos & 78 & 5.27 \\
Viveros & 103 & 6.96 \\
Alameda & 167 & 11.28 \\
Palau & 399 & 26.96 \\
Gulliver & 111 & 7.50 \\
Ciudad de las Artes & 295 & 19.93 \\
Total & 1480 & 100.00 \\
\hline
\end{tabular}


The second section, focused on valuation questions, as is customary in contingent valuation exercises. In order to obtain honest responses, before the respondents were asked about their WTP, they were reminded about (i) their household income restraint; (ii) that there are other public goods which they could be asked to pay for; (iii) the current amount in Euro that the average citizen of Valencia pays each year in taxes to the city council. In particular, the WTP question was worded in this way:

"Now I want to ask you how much you would be willing to pay each year in extra property taxes considering the whole array of benefits that you receive every time you visit the park. Before answering, please remember that:

1. The average citizen of Valencia is currently paying $253 €$ per year in property taxes.

2. Your personal and familiar income is limited, so any additional money you would pay in extra taxes would not be available to you for other purchases.

3. There are others public goods to which you could be asked to pay for.

The payment vehicle chosen was an annual increase in the local taxes paid by the respondents. In Spain, in order to make more efficient the tax collection system, the citizens practically only pay a single tax to the local authorities known as 'Impuesto de bienes inmuebles' (the urban real state tax). This payment vehicle was considered to be realistic in so far as such taxes are familiar to everybody and the fact that respondents were told that the additional tax collection would be directed at the enhancement and improvement of the park's current facilities. Bateman et al. (2003) tested different payment vehicles and found that although a tax payment vehicle may give a stated WTP that is lower than the true WTP, this stated amount is substantially higher than the stated amount obtained with voluntary donations to trust funds.

The survey concluded with demographic and economic questions about the respondents and their households: their gender, their year of birth, their income after tax, the amount of formal education they have completed, the number of people they usually live with, the frequency and duration of their visits, the activities that they pursue in the park, etc. The information gathered from this section of the questionnaire is very useful in validating the results obtained from a theoretical point of view, as will be seen later.

\section{Theoretical model}

\subsection{A measure of utility change}

Following Johansson (1993), let us consider an individual that maximizes his utility subject to budget constraint. Then, the individual's indirect utility function can thus be written as:

$V=U[x(p, y, z), z]=V(p, y, z)$

where $x$ is a $1 \cdot n$ vector of private goods and $z$ is a $1 \cdot m$ vector of public goods. The quantity demanded of private goods is a function of prices $(p)$, income $(y)$ and the provision or quality of environmental commodities $(z)$. The indirect utility function is decreasing in prices, and increasing in income and the quality of the environment.

Let us now introduce a change in the environmental quality. Then the change in utility is:

$\Delta V=V\left(p, y, z^{1}\right)-V\left(p, y, z^{0}\right)$

where a superscript 0 (1) denotes initial (final) levels values for the environmental good. Since the utility function is not observable, we need a money measure to evaluate the change in utility. Then let us consider the compensating variation or CV in short. This is an amount of money that:

$V\left(p, y-\mathrm{CV}, z^{1}\right)=V\left(p, y, z^{0}\right)$

The CV represents the maximum amount of money that can be taken from the individual while leaving him just as well off as prior to the improvement. In other words, the CV is the WTP for an improvement in environmental quality. In our particular case, the individual who visits the park experiences an increase in his utility or well-being as a consequence of the different benefits that are obtained from using the park. This individual is therefore willing to pay an amount of money in order to secure this utility gain.

\subsection{Tobit model versus Double-Hurdle model}

A recurrent problem linked with the use of open-ended questions in contingent valuation studies is that some respondents frequently state a zero WTP for the environmental change under analysis. There are several reasons for this. Such respondents might not value the environmental change positively due to the fact that it does not enter into their preference function or because they may find it difficult to "pick a value out of the air" if they are not familiar with having to pay for the good (Mitchell and Carson, 1989). Therefore, as normally nobody states a negative bid value, something that was also found to be the case in our survey, a large number of responses cluster around the zero value. The analysis of open-ended bids has traditionally been addressed using standard ordinary least-square regressions ignoring the censoring implied by zero bids. The failure to recognize explicitly the censored or truncated distribution of bids in open-ended contingent valuation surveys results in biased and inconsistent estimates of the parameters (Halstead et al., 1991; Maddala, 1983). A straightforward way of addressing this problem is the Tobit model (Tobin, 1958) that recognizes that WTP values are censored at zero (see, for example, Bateman et al., 2006; Piper and Martin, 2001; Stumborg et al., 2001; Berrens, 2000; Yoo et al., 2000; Alvarez-Farizo et al., 1999; Whitehead et al., 1995).

However, the Tobit model only allows for one type of zero observations, namely a corner solution or non-use situation, since it is based on the implicit assumption that zeros arise only as a result of the respondent's economic circumstances (Martínez-Espiñeira, 2006). Therefore, alternative empirical procedures that are less restrictive may offer significant advan- 
tages if is assumed that the use/non-use rule is generated by a process that differs from the process generating the continuous non-zero bids (Goodwin et al., 1993), i.e. the process that governs the two decisions that the individual may take, to participate or not in the market for the public, or environmental, good and the stated degree of support, are different.

Empirical models with censored distributions that allow for the possibility that these two decisions are affected by a different set of variables are referred in the literature as "Double-Hurdle" models (Cragg, 1971). This name refers to the two obstacles that must be overcome before a positive value of the dependent variable is observed.

If both processes are the same, the following censoring rule is appropriate:

$$
\begin{aligned}
& y_{i}=y_{i}^{*}, \quad \text { if } y_{i}^{*}>0 \\
& y_{i}=0, \quad \text { otherwise } \\
& y_{i}^{*}=X_{i} \beta+e_{i}
\end{aligned}
$$

where $y_{i}$ is the revealed WTP for individual $i, y_{i}^{*}$ the corresponding latent value of individual $i$ 's actual WTP, $e_{i} \sim N\left(0, \sigma^{2}\right), X_{i}$ a vector of the individual's characteristics and $\beta$ is a vector of parameters. In this case a standard Tobit model is appropriate. Alternatively, if the two processes under consideration differ, the appropriate censoring rule is given by this equation:

$$
\begin{aligned}
& y_{i}=y_{i}^{*}, \quad \text { if } y_{i}^{*}>0 \text { and } D_{i}>0 \\
& y_{i}=0, \quad \text { otherwise } \\
& D_{i}=Z_{i} \theta+u_{i}
\end{aligned}
$$

where $D_{i}$ is a latent variable describing the participate/nonparticipate decision, $u_{i} \sim N\left(0, \sigma^{2}\right), Z_{i}$ a vector of explanatory variables that are related to the discrete participate/nonparticipate decision and $\theta$ is a vector of parameters.

Assuming that for each respondent the decision whether or not to participate in the market and the decision about the level of participation are made independently, the estimation of the Double-Hurdle model requires first the estimation of a Probit model to evaluate the censoring rule $\left(Z_{i} \theta\right)$ and, second, the estimation of a Truncated regression model to obtain the bid function $\left(X_{i} \beta\right)$ for the subsample of censored observations.

\section{Empirical results}

Of the full sample, only 25 individuals were unable to state a WTP despite the fact that we used an open-ended question that is more difficult to answer than a close-ended one. However, the percentage of zero bids was very high since $79 \%$ of the respondents stated a zero WTP value. Although this is a striking result, Johnson and Whitehead (2000) point out that for many policy issues WTP questions generate a considerable number of zero responses. Moreover, this results is quite similar to the $77 \%$ of zero bids obtained by Kriström (1997) using an openended question, and to the $65 \%$ reported by Saz and GarcíaMenéndez (2003). If we exclude the protest responses $(47.7 \%)$ from our sample, this figure drops to a reasonable $31.2 \%$ (see Table 2). A total of $33 \%$ of those stating a zero WTP claimed
Table 2

Distribution of WTP responses

\begin{tabular}{lllc}
\hline WTP & \multicolumn{2}{l}{ Income reported? } & \\
\cline { 2 - 4 } & No & Yes & Total \\
\hline Protest & $86(58.1)$ & $609(46.6)$ & $695(47.7)$ \\
Zero & $46(31.1)$ & $408(31.2)$ & $454(31.2)$ \\
Positive & $16(10.8)$ & $290(22.2)$ & $306(21.1)$ \\
Total & 148 & 1307 & 1455 \\
\hline
\end{tabular}

Percentages in parenthesis.

not to care about the park or lack of income, while the main reason for protesting was that the respondents felt they already paid too much tax. In general, these prior findings could suggest considerable resistance to the elicitation format used, or that respondents are not used to participating in decision-making, as is the case in Spain.

An important issue in CV research is the treatment of individuals for whom some information is missing in the data set of explanatory variables. For example, usually income is a question that respondents tend to be reluctant to answer. This variable is a key factor in explaining differences across individuals in their WTP for a good or service. In our case, as is shown in Table 2, a $10.2 \%$ of respondents refused to answer this question, while Alvarez-Farizo et al. (1999) reported a higher percentage $(19.5 \%)$. Here, the problem could arise if there is some relationship between income non-response and type of bid made suggesting, for example, that income non-reporting and protest bidding is not a random process. If it is the case, missing information of the explanatory variables of interest could result in a sample selection bias problem when estimating willingness to pay equations. In our case, although respondents who refused to answer the income question appear to have a slight tendency to report protest bids compared to respondents who reported their income (i.e. $58.1 \%$ compared to $46.6 \%$ ), this difference is not so evident, an hence problematic, as the difference by 24.5 percentage points reported by Alvarez-Farizo et al. (1999) for an Environmental Sensitive Area in Scotland. In addition, if we consider the genuine zeros there is no difference between those who did not reported their income and those other that reported it because they represent the same percentage (31\%).

In Table 3 we present the mean WTP using the continuous data and excluding the protest responses, as is customary in CV exercises. In this respect, such responses are defined as zero WTP values given in protest against a particular aspect of the hypothetical market presented to the respondents. Normally, these respondents value the public good under consideration positively. However, they reject the payment for several reasons, as has been mentioned in the previous paragraph. When calculating the mean WTP, we distinguished among the different sections of the park where the interview was conducted. The mean WTP for the full sample is $7.6 €$ with a standard error of $19.11 €$, while some sections exhibit a higher value due to the particular facilities that they offer to the visitors, as in the case of the section named "Atletismo" and "Serranos" which are the only sections with sporting facilities. The high valuation of the sec- 
Table 3

Mean WTP by section of the park $(€)$

\begin{tabular}{lccc}
\hline Section & Mean WTP & Standard deviation & Maximum WTP \\
\hline Parque de cabecera & 7.35 & 16.79 & 100 \\
Campanar & 6.80 & 8.43 & 20 \\
Atletismo & 10.92 & 21.74 & 90 \\
Bosque Mediterráneo & 10.98 & 28.86 & 150 \\
Serranos & 9.56 & 21.67 & 100 \\
Viveros & 5.83 & 9.18 & 50 \\
Alameda & 8.79 & 20.38 & 150 \\
Palau & 9.00 & 19.42 & 150 \\
Gulliver & 2.66 & 7.35 & 40 \\
Ciudad de las Artes & 4.73 & 17.95 & 150 \\
Full sample & 7.60 & 19.11 & 150 \\
\hline
\end{tabular}

Source: Our own calculations.

tion "Bosque Mediterráneo" is due, we believe, to the amenity value of this section which is characterised by exuberant vegetation. In the "Alameda" section the high value obtained could be explained by the fact that this section goes around the highest income areas of the city. The low value obtained in the "Gulliver" could be explained, conversely, by the fact that this section is next to lowest income areas of the city. The low valuation of the section "Ciudad de las Artes" could be due to the previously mentioned fact that this section houses several museums and recreation facilities for which an entry fee is charged. It would seem, therefore, that people are not willing to pay any more for using the free-access recreation area that surrounds these feepaying facilities. In fact, both the number of protest bids as the number of real zeros are very high in this area reaching an overall percentage of $88 \%$. In any case, these early findings should be considered with caution until we have estimated a valuation or bid function.

In order to get an idea of how much the WTP obtained is we deemed it appropriate to compare this figure with the money that the city council is currently spending on the maintenance of gardens and parks. So, as is shown in Table 4, the total cost spent on the maintenance of parks and gardens is divided by the number of households and multiplied by the relative surface of "Jardín del Túria" $(26.76 \%)$ obtaining that the average expenditure in this park per household is $4.62 €$. If we now compare this latter figure with the estimated WTP $(7.60 €)$ we can see that the benefits derived from the use of the park are a $64 \%$ higher than the provision costs. As it is rather obvious, this direct comparison can lead us to conclude quickly that this it is a social optimum. However, to be accurate it would be necessary to consider both the investment made throughout the years as the alternative benefits that would arise if the area covered by the park had been dedicated to alternative uses. Regarding this latter issue, the only alternative use that many years ago was contemplated for this area was the construction of a motorway given its transversal layout from west to east. Fortunately, this alternative option, strongly influenced by the prevailing at-allcosts development vision of the late sixties and early seventies before the oil crisis, was rejected because it had meant a clear deterioration of the environmental quality.

Now we could wonder if positive WTP values are realistic or not. So, from the data obtained both from the property cadastre as the City Council Office for Economic and Finances Affairs, we know that $155,775,000 €$ were collected in 2005 in property taxes and that the number of real states units - of all kind - was 614,690 , then the average amount paid by an owner in property taxes was $253.4 €$. Therefore, the mean WTP obtained means an increase of $2.5 \%$ for an average property tax, what represents a very reasonable increase being at all unrealistically high.

The empirical analysis of the bid function was conducted in such a way as to allow a comparison of the Tobit model with the Double-Hurdle model. Of the 1455 interviews with a stated WTP, 666 were completed to the extent necessary for regression analysis, once the protest responses and any observation with item non-response on any variable in the questionnaire have been dropped. In Table 5 we present the description of the variables used in the empirical analysis. The dependent variable is the WTP (in Euros) stated by the individual in the open-ended question, while independent variables include the respondent's household income, level of education, three dummy variables equal to one if the interview was conducted in the sections called "Alameda", "Ciudad de las Artes" and "Gulliver", age, frequency of visits, and a last dummy variable equal to one if the respondent is of Spanish nationality.

The results for the Tobit model are reported in two first columns of Table 6 , while the other columns show the results of the Double-Hurdle model using the same set of explanatory variables. A specification test that evaluates the Double-Hurdle model against the Tobit model is directly obtained through a comparison of the log-likelihood functions values of the Tobit, Probit and Truncated models estimated. Assuming that the same set of explanatory variables appears in all three equations estimated, the following value $\lambda$ will be distributed as a chi square random variable with degrees of freedom equal to the number of explanatory variables under the null hypothesis that the Tobit model is the correct specification (Goodwin et al., 1993):

$\lambda=-2\left(L_{\mathrm{T}}-L_{\mathrm{P}}-L_{\mathrm{TR}}\right)$

where $L_{\mathrm{T}}$ is the likelihood for the Tobit model, $L_{\mathrm{P}}$ the likelihood for the Probit model and $L_{\mathrm{TR}}$ is the likelihood for the truncated model. In our particular case, this statistic has a value of 177.40, which exceeds the Chi-square critical value of 21.66 at the $\alpha=0.01$ level of significance and thus rejects the use of the Tobit model in favour of the two-step model (Probit plus Truncated regression). This result suggests that the decision to

Table 4

Expenditure per capita on the maintenance of gardens and parks (2005)

\begin{tabular}{|c|c|c|c|}
\hline Current expenditure on the maintenance of gardens and parks ( $€$ ) & City population & Number of households & Expenditure per household (€) \\
\hline $4,988,356$ & 807,396 & 288,355 & 17.30 \\
\hline
\end{tabular}

Source: Ajuntament de Valencia (2006), Anuari Estadistic de la Ciutat de Valencia. Ajuntament de Valencia. 
Table 5

Description of the explanatory variables

\begin{tabular}{|c|c|c|}
\hline Variable & Description & Rationale \\
\hline INCOME & $\begin{array}{l}\text { Respondent's household monthly income after taxes in four } \\
\text { different intervals ranging from } 0 \text { to } 3000 €\end{array}$ & WTP for recreation tends to rise with income \\
\hline EDUCATION & $\begin{array}{l}\text { Respondent's formal education completed in five different } \\
\text { intervals ranging from secondary education to higher } \\
\text { education at university }\end{array}$ & Education tends to be positively correlated with environmentalism \\
\hline CABECERA & $\begin{array}{l}\text { Dummy variable equal to one if the interview was conducted } \\
\text { in the section called "Parque de Cabecera" }\end{array}$ & $\begin{array}{l}\text { Stated WTP may depend on the section of the park were the interview } \\
\text { was conducted }\end{array}$ \\
\hline GULLIVER & $\begin{array}{l}\text { Dummy variable equal to one if the interview was conducted } \\
\text { in the section called "Gulliver" }\end{array}$ & $\begin{array}{l}\text { Stated WTP may depend on the section of the park were the interview } \\
\text { was conducted }\end{array}$ \\
\hline CIUDAD & $\begin{array}{l}\text { Dummy variable equal to one if the interview was conducted } \\
\text { in the section called "Ciudad de las Artes" }\end{array}$ & $\begin{array}{l}\text { Stated WTP may depend on the section of the park were the interview } \\
\text { was conducted }\end{array}$ \\
\hline AGE & Respondent's age & Attitudes towards parks may be correlated with age \\
\hline FREQUENT & $\begin{array}{l}\text { Dummy variable equal to one if the respondent visits the park } \\
\text { more than five times per month }\end{array}$ & The higher is the frequency of visits the higher is the stated WTP \\
\hline SPANISH & $\begin{array}{l}\text { Dummy variable equal to one if the respondent's nationality } \\
\text { is Spanish }\end{array}$ & Stated WTP may depend on respondent's nationality \\
\hline
\end{tabular}

state a positive value (participate or not participate in the market) and the decision about how much to pay (the degree of support) appear to be governed by different processes, making the Tobit model inappropriate to explain why some respondents state a zero value. Marginal effects of changing the explanatory variables on the continued bid levels for the Tobit and truncated models are evaluated at the mean of the explanatory variables, while in the case of the Probit model the marginal effects show the effects of changing the explanatory variables on the probability of participating or not in the market also evaluated at the mean values of the explanatory variables.

The Tobit model indicates that willingness to pay is significantly and positively influenced by income, as was expected. The construction of an equation that predicts WTP for the good with reasonable explanatory power and coefficients with the expected signs provides evidence for the proposition that the survey has measured the intended construct (Carson, 2000; Bishop et al., 1995). The partial derivate for this variable suggests that will- ingness to pay rises by $2.56 €$ for each additional increase in the INCOME intervals. Likewise, EDUCATION is positively related to willingness to pay, and each education level completed increases willingness to pay by $1.26 €$.

The relationship between willingness to pay and the section of the park where the interview was conducted has been addressed by taking into consideration only the variables that were significant at the 0.10 level or above. As a result, we only have three significant variables in our models. The results obtained show that if the interview was conducted in the "Parque de Cabecera", "Ciudad de las Artes" and "Gulliver" sections the willingness to pay is, respectively, $4.08 €, 7.52 €$ and $7.51 €$ lower than the values reported in the sections omitted in the regression. These results are consonant with the prior findings shown in Table 3, where at least two of these three sections exhibit values clearly under the mean willingness to pay.

The AGE variable shows a positive relationship to willingness to pay in such a way that each additional year increases

Table 6

Tobit model versus Double-Hurdle model

\begin{tabular}{|c|c|c|c|c|c|c|}
\hline & \multicolumn{3}{|l|}{ Tobit analysis } & \multicolumn{3}{|c|}{ Double-Hurdle analysis } \\
\hline & Tobit coefficients & Marginal effects & Probit coefficients & Marginal effects & Truncated coefficients & Marginal effects \\
\hline CONSTANT & $-38.6998(-4.94)$ & $-13.4205(-5.267)$ & $-1.2510(-5.345)$ & $-0.4735(-5.455)$ & $-408.2627(-4.511)$ & $-22.1831(-4.511)$ \\
\hline INCOME & $7.4056(4.181)$ & $2.5688(4.190)$ & $0.2068(3.753)$ & $0.0782(3.756)$ & $45.3039(3.180)$ & $2.4616(3.180)$ \\
\hline EDUCATION & $3.6252(2.984)$ & $1.2670(2.998)$ & $0.1351(3.527)$ & $0.0511(3.532)$ & $-2.2695(-0.200)$ & $-0.1233(-0.200)$ \\
\hline CABECERA & $-11.7854(-1.969)$ & $-4.0880(-1.973)$ & $-0.4510(-2.462)$ & $-0.1707(-2.463)$ & $31.1564(0.462)$ & $1.6928(0.462)$ \\
\hline CIUDAD & $-21.6995(-4.569)$ & $-7.5270(-4.634)$ & $-0.7485(-5.228)$ & $-0.2833(-5.249)$ & $-17.7060(-0451)$ & $-0.9620(-0451)$ \\
\hline GULLIVER & $-21.6651(-2.592)$ & $-7.5151(-2.602)$ & $-0.6507(-2.607)$ & $-0.2463(-2.609)$ & $-72.5995(-1.600)$ & $-3.9447(-1.600)$ \\
\hline AGE & $0.2906(2.710)$ & $0.1008(2.711)$ & $0.0080(2.449)$ & $0.0030(2.449)$ & $3.1317(2.887)$ & $0.1701(2.887)$ \\
\hline FREQUENT & $-9.2096(-2.163)$ & $-3.1946(-2.168)$ & $-0.3609(-2.758)$ & $-0.1366(-2.759)$ & $-13.4887(-0.302)$ & $-0.7329(-0.302)$ \\
\hline SPANISH & $-9.0313(-1.972)$ & $-3.1327(-1.965)$ & $-0.0351(-0.242)$ & $-0.0133(-0.242)$ & $-98.9184(-2.061)$ & $-5.3747(-2.061)$ \\
\hline$\sigma$ & 34.95 & & & & 74.54 & \\
\hline Log-L & -1514.512 & & -418.1960 & & -1007.614 & \\
\hline Pseudo $R^{2}$ & & & 0.1766 & & & \\
\hline
\end{tabular}

$\chi^{2}$ test Double-Hurdle versus Tobit, $\lambda=177.40>\chi^{2}(9)=21.66$

Note: $t$-Values are shown in parenthesis. The Pseudo $R^{2}$ computed is that proposed by Veall and Zimmermann (1992). 
willingness to pay by only $0.01 €$. Another interesting result is that the higher the frequency of visits to the park, the lower the visitor's willingness to pay. In fact, the coefficient of the FREQUENT variable shows that these individuals have a willingness to pay $3.19 €$ less than individuals who visit the park less frequently. It seems logical that the higher the number of visits is the lower is the utility received by each visit. Willingness to pay, therefore, is also lower. However, this result deserves more attention. In fact, if the payment vehicle considered is an annual increase in the property taxes paid by each household, it seems reasonable that the higher is the use of the park, and hence the benefits obtained from it, the higher should be the WTP. So, the correct sign expected by this variable in this particular case should be positive instead the negative one obtained.

Finally, the negative sign of the SPANISH variable shows that non-residents in Spain are more willing to pay than the Spaniards. In particular, if the respondent is a Spaniard his willingness to pay is $3.12 €$ lower than in the case of non-Spanish visitors. This result also deserves a further explanation since it could be misleading. We said in the previous sections of the paper, that the "Ciudad de las Artes" area receives the majority of the foreign visitors and now, once the bid function has been estimated, we can deduce from the interpretation of the variable SPANISH that precisely foreign visitors exhibit a higher WTP than Spanish visitors. So, it seems that this interpretation is in contradiction with the sign of the variable CIUDAD that is precisely showing that in this area the WTP is lower than in the rest of areas considered in the survey study. Given that protest responses were dropped when the bid function was estimated, as is usual in contingent valuation studies, the lower WTP of this area only could be explained by the fact that it exhibited a higher rate of genuine zero responses than the rest of areas analysed. Indeed, the percentage of genuine zeros in this area is the highest one of all of them, reaching a $40 \%$ while for the whole sample is ten percentage points lower. Besides, if we now distinguish between residents and non-residents in Valencia, we can see that in this section of the park those who gave a genuine zero response were mainly residents in Valencia (75\%) against non-residents that account for only a $25 \%$.

Given that from the available information, it seems that location and income could be highly correlated leading to econometric problems if both variables are included simultaneously in the estimated equation, we have considered advisable to check the problem of multicollinearity. The corresponding correlation matrix is reported in Table 7 and, from its observation, we can conclude, in general, that multicollinearity is not a serious problem and, in particular, that there is not apparent relationship between income and each one of the three location variables considered.

As mentioned above, the test performed rejected the restrictions implicit in the Tobit model in favour of the two-step model that relates the enter/non-enter decision with the continuous willingness to pay stated in the open-ended question. The Probit coefficients estimated, and the implied marginal effects, are contained in the third and fourth columns of Table 6, respectively, while the last two columns contain those coefficients that relate to the Truncated model. The decision to enter the market or not is explained by the same set of variables as in the Tobit model. However, in this case the SPANISH variable, although exhibiting the same sign, is not significant. The marginal probability results (fourth column) indicate that the probability of entering the market rises by $7.8 \%$ for each additional increase in income intervals. Likewise, each additional education level completed raises this probability by $1.3 \%$. However, if the interview was conducted in some of the three sections of the park considered, the probability of entering the market decreases sharply. As in the Tobit model, another interesting, and unexpected, result is that the higher the number of visits is, the lower is the probability of accepting to pay a positive amount. In fact, those individuals defined as frequent visitors are $13.6 \%$ less likely to be willing to pay. The effect of each additional year of age on the probability of entering the market is the lowest: only a $0.3 \%$.

In the Double-Hurdle model, the Truncated model estimated shows, once the respondent has decided to participate in the market, the stated degree of support given by those individuals with a positive willingness to pay. In contrast with the Tobit model, the fifth column shows that the variables representing the different sections of the park, the level of education, and the frequency of visits are not significant. However, the remaining variables are significant, and, more importantly, the main variable, INCOME, is highly significant and exhibits the expected sign according to economic theory. In particular, the marginal effects show that each additional income level increases the willingness to pay by $2.46 €$, a result that is very similar to the one obtained in the Tobit model since the coefficients are almost identical in value. Regarding the nationality, if the respondent interviewed had Spanish nationality this fact decreased willingness to pay by $5.37 €$ while in the Tobit model the effect was also negative but smaller.

Table 7

The correlation matrix

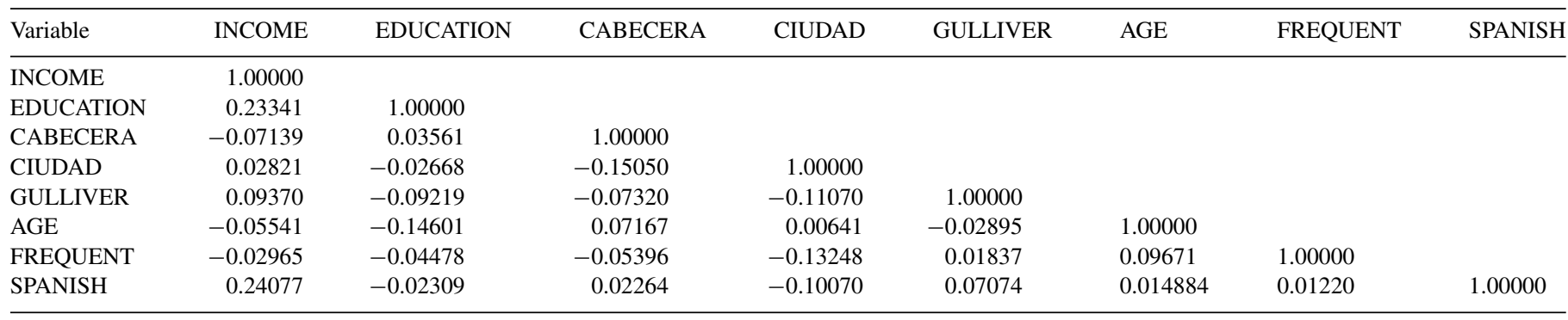




\section{Aggregation}

Our purpose here is to show the utility of the contingent valuation method in decision-making. Therefore, we want to estimate the social benefits arising from the use of this park by the citizens of Valencia. Although the contingent valuation method allows us to capture more values than the indirect methods, we think that considering how the valuation question was worded, we are capturing mainly use values although the respondent may have other benefits in mind when responding the valuation question.

So, given that the payment vehicle used was an annual increase in the current real state tax paid by owners, aggregation must be made on a per capita basis and by flat owners. According to INE (Spanish National Statistics Institute) data the average size of a family in Valencia is 2.80 people. If we divide the population of Valencia by this figure, we arrive at a figure of 288,355 for the number of families living in Valencia (see Table 8). If we know multiply the mean WTP obtained $(7.60 €)$ by the number of families we can conclude that the social benefits derived from the use of this park are equivalent to $2,191,498 €$ per year. In the same way, instead of the number of families we could use the number of houses in Valencia that, according to INE data, amounts to 390,609 houses. So, if again we multiply this figure by the mean WTP the social benefits will be equivalent to $2,803,032 €$, a figure that is higher than the previous one.

Let us now suppose that the park is expected to have a useful life of 25 years, and following Almansa and Requena (2007) let us assume a discount rate between 1 and 3\% considering the long-term nature of many environmental benefits as is the case here. In this respect, is necessary to say that apart from the recreational benefits that a park offers to its visitors, the presence of trees and vegetation can play an important role in reducing air pollution, thus affecting not only the welfare of the current generation but also that of the future generations. Therefore, the received view is that a lower discount rate for the longer term should be used. The main rationale for declining long-term discount rates stems from uncertainty about the future (Weitzman, 1998, 2001). So, when we consider the number of families, the net present value (NPV) of the expected social benefits ranges from a maximum value of 48.2 million $€$ if we apply a discount rate of $1 \%$ and a minimum value of 38.1 million $€$ if the discount rate considered is $3 \%$. And, if we consider again the number of houses, the net present value of the expected social benefits ranges from a maximum value of 61.7 million $€$ if we apply a discount rate of $1 \%$ and a minimum value of

Table 8

Estimation of the social benefits

\begin{tabular}{lll}
\hline Population of Valencia & 807,396 & - \\
Number of families & 288,355 & - \\
Number of houses & - & 390,609 \\
Mean WTP $(€)$ & 7.60 & 7.60 \\
Annual social benefits $(€)$ & $2,191,498$ & $2,803,032$ \\
$\quad$ Expected social benefits assuming a period & $48,263,701$ & $61,731,610$ \\
$\quad$ of 25 years and a discount rate of 1\% $(€)$ & & \\
Expected social benefits assuming a period & $38,160,878$ & $48,809,610$ \\
$\quad$ of 25 years and a discount rate of 3\% $(€)$ & & \\
\hline
\end{tabular}

Source: Our own calculations and INE data.
48.8 million $€$ if the discount rate considered is $3 \%$. In any case, these figures must be considered with caution because they are an approximation, obtained taken some assumptions, to the real value of the social benefits arising from this park.

\section{Discussion}

This survey research was specifically designated to accomplish the main goal of determining how people value green areas in urban environments. Although this topic has been addressed profusely in the literature, as it has been shown in the introduction section, we believe that our contribution is significant at least in three aspects. First, these valuation studies must be assessed in the specific context in which they are conducted. Therefore, in a context as the Spanish society characterised by a low degree of public participation in public decisions ( $\mathrm{Saz}$ and García-Menéndez, 2003), we think that this kind of survey studies, and the information that they provide, have an important relevance for decision-making. Second, besides the estimation of the social benefits that stem from the recreational use of this park, we also dealt with the issue of zero responses by applying a Double-Hurdle model. While the use of Tobit models for analysing WTP - in open-ended contingent valuation studies is a common phenomenon in the literature, we cannot say the same about the Double-Hurdle model. This latter, has a clear advantage over the former: it accounts for the two decisions taken by the respondent (participate/non-participate in the market and the amount his is willing to pay). And third, an attempt was made to analyse the relationship between WTP and the section of the park where the interview was conducted. The results obtained show that depending of the uses of each section and the kind of people that visit it, the WTP is different. Besides, another interesting finding is that non-residents in Spain show a higher WTP than the Spanish visitors. Given the cultural differences between both groups, this result seems to confirm the idea advanced by Tyrväinen et al. (2007) when they say that the demand for various green areas qualities is culturally dependent.

\section{Conclusions}

In this paper the CVM has been applied to measure the nonmarket benefits arising mainly from the use of an urban park in a big city. Given public awareness about the role played by parks and open spaces in promoting public well-being in urban areas, there is an increasing need to provide local authorities with valuable information that can be used in decision-making, as is the case under consideration. Assuming a useful life for the park of 25 years a conservative estimate of the present value of the expected social benefits ranges from a minimum value of 38.1 million $€$ if the discount rate considered is $3 \%$, and a maximum value of 61.7 million $€$ if we apply a discount rate of $1 \%$.

Our CVM estimate of non-market benefits has passed some minimal test of theoretical validity although we are aware that this survey method has some flows, as any economic methodology. Our results show with reasonable explanatory power that WTP increases with income and education as expected. They 
also show that WTP varies depending on which section of the park the interview was conducted in. This result is apparently explained by the different facilities offered by each section, and also by the income level of the adjacent areas.

Apart from the simple estimation of WTP and its determinants, we have dealt with the problem of zero bids in open-ended contingent valuation surveys. The specification test performed has strongly rejected the Tobit model in favour of the more flexible Double-Hurdle model. This latter model indicates that the set of explanatory variables considered influences the participate/non-participate decision in a different manner than the decision about how much the individual is willing to pay.

\section{Acknowledgements}

The authors are especially grateful to the anonymous reviewers for their helping and encouraging comments on the earlier draft of this manuscript.

\section{References}

Almansa Sáez, C., Calatrava Requena, J., 2007. Reconciling sustainability and discounting in cost benefit analysis: a methodological proposal. Ecol. Econ. 60, 712-725.

Alvarez-Farizo, B., Hanley, N., Wright, R.E., MacMillan, D., 1999. Estimating the benefits of agri-environmental policy: econometric issues in open ended contingent valuation studies. J. Environ. Plan. Manage. 42, 23-43.

Arrow, K., Solow, R., Portney, P.P., Leamer, E.E., Radner, R., Schuman, H., 1993. Report of the national oceanic and atmospheric administration panel on contingent valuation. Fed. Register 58, 4602-4614.

Barreiro, J., Sánchez, M., Viladrich-Grau, M., 2005. How much are pople willing to pay for silence? A contingent valuation study. Appl. Econ. 37, 1233-1246.

Bateman, I.J., Cole, M.A., Georgiu, S., Hadley, D.J., 2006. Comparing contingent valuation and contingent ranking: a case study considering the benefits of urban river quality improvements. J. Environ. Manage. 79, 221-231.

Bateman, I.J., Lovett, A.A., Brainard, J.S., 2003. Applied Environmental Economics: A GIS Approach to Cost-Benefit Analysis. Cambridge University Press, Cambridge.

Bengochea, A., 2003. A hedonic valuation of urban green areas. Land. Urban Plan. 66, 35-41.

Berrens, R.P., 2000. Reluctant respondents and contingent valuation surveys. Appl. Econ. Lett. 7, 263-266.

Bishop, R.C., Champ, P.A., Mullarkey, D.J., 1995. Contingent valuation. In: Bromley, D.W. (Ed.), The Handbook of Environmental Economics. Blacwell, Cambridge, pp. 626-654.

Bolitzer, B., Netusil, N.R., 2000. The impact of open spaces on property values in Portland, Oregon. J. Environ. Manage. 59, 185-193.

Breffel, W.S., Morey, E.R., Lodder, T.S., 1998. Using contingent valuation to estimate a neighbourhood's willingness to pay to preserve undeveloped urban land. Urban Stud. 35, 715-727.

Carson, R.T., 1991. Constructed markets. In: Braden, J.B., Kolstad, C.D. (Eds.), Measuring the Demand for Environmental Quality. North Holland, Amsterdam.

Carson, R.T., 1998. Valuation of tropical rainforest: philosophical and practical issues in the use of contingent valuation. Ecol. Econ. 24, 15-29.

Carson, R.T., 2000. Contingent valuation: a user's guide. Environ. Sci. Technol. $34,1413-1418$

Chiesura, A., 2004. The role of urban parks for the sustainable city. Land. Urban Plan. 68, 129-138.

Cragg, J., 1971. Some statistical models for limited dependent variables with application to the demand for durable goods. Econometrica 39, 829-844.

Damigos, D., Kaliampakos, D., 2003. Assesing the benefits of reclaiming urban quarries: ACVM analysis. Land. Urban Plan. 64, 249-258.
Diamond, P.A., 1996. Testing the internal consistency of contingent valuation surveys. J. Environ. Econ. Manage. 30, 337-347.

Diamond, P.A., Hausman, J.A., 1993. On contingent valuation measurement of nonuse values. In: Hausman, J.A. (Ed.), Contingent Valuation: A Critical Assessment. North-Holland, Amsterdam, pp. 3-38.

Diamond, P.A., Hausman, J.A., 1994. Contingent valuation: is some number better than no number? J. Econ. Perspect. 8, 45-64.

Din, A., Hoesli, M., Bender, A., 2001. Environmental variables and real state prices. Urban Stud. 38, 1989-2000.

Freeman, A.M., 1993. The Measurement of Environmental and Resource Values: Theory and Methods. Resources for the Future, Washington DC.

Geoghegan, J., 2002. The value of open spaces in residential land use. Land Use Policy 19, 91-98.

Goodwin, B.K., Offenbach, L., Cable, T.T., Cook, P.S., 1993. Discrete/continuous contingent valuation of private hunting access in Kansas. J. Environ. Manage. 39, 1-12.

Halstead, J.M., Lindsay, B.E., Brown, C.M., 1991. Use of the Tobit model in contingent valuation: experimental evidence from the Pemigewasset Wilderness Area. J. Environ. Manage. 33, 78-89.

Hausman, J. (Ed.), 1993. Contingent Valuation: A Critical Assessment. NorthHolland, Amsterdam.

Hobden, D.W., Laughton, G.E., Morgan, K.E., 2004. Green space borders-a tangible benefit? Evidence from four neighbourhoods in Surrey, British Columbia, 1980-2001. Land Use Policy 21, 129-138.

Jim, C.Y., Chen, W.Y., 2006a. Impacts of urban environmental elements on residential housing prices in Guangzhou (China). Land. Urban Plan. 78, 422-434.

Jim, C.Y., Chen, W.Y., 2006b. Recreation-amenity use and contingent valuation of urban greenspaces in Guangzhou, China. Land. Urban Plan. 75, 81-96.

Johansson, P.-O., 1993. Cost-Benefit Analysis of Environmental Change. Cambridge University Press, Cambridge.

Johnson, B.K., Whitehead, J.C., 2000. Value of public goods from sports stadiums: the CVM approach. Contemp. Econ. Policy 18, 48-58.

Kriström, B., 1997. Spike models in contingent valuation. Am. J. Agric. Econ. 79, 1013-1023.

Loomis, J., Rameker, V., Seidl, A., 2004. A hedonic model of public market transactions for open space protection. J. Environ. Plan. Manage. 47, 83-96.

Luttik, J., 2000. The value of trees, water and open space reflected by house prices in the Netherlands. Land. Urban Plan. 48, 161-167.

Maddala, G.S., 1983. Limited Dependent and Qualitative Variables in Econometrics. Cambridge University Press, New York.

Mansfield, C., Pattanayak, S.K., McDow, W., McDonald, R., Halpin, P., 2005. Shades of green: measuring the value of urban forests in the housing market. J. For. Econ. 11, 177-199.

Martínez-Espiñeira, R., 2006. A Box-Cox Double-Hurdle model of wildlife valuation: The citizen's perspective. Ecol. Econ. 58, 192-208.

Mitchell, R.C., Carson, R.T., 1989. Using Surveys to value Public Goods: The Contingent Valuation Method. Resources for the Future, Washington DC.

Mitchell, R.C., Carson, R.T., 1995. Current issues in the design, administration, and analysis of contingent valuation survey. In: Johansson, P.O., Kriström, B., Mäller, K.G. (Eds.), Current Issues in Environmental Economics. Manchester University Press.

Palmquist, R.D., 1992. Valuing localised externalities. J. Urban Econ. 31, 59-68.

Piper, S., Martin, W.E., 2001. Evaluating the accuracy of the benefit transfer method: a rural water supply application in the USA. J. Environ. Manage. 63, 223-235.

Powe, N.A., Garrod, G.D., Willis, K.G., 1995. Valuation of urban amenities using a hedonic price model. J. Property Res. 12, 137-147.

Rosen, S., 1974. Hedonic prices and implicit markets: product differentiation in pure competition. J. Polit. Econ. 82, 34-55.

Saz, S.D., García-Menéndez, L., 2007. Estimating the non-market benefits of an urban park: does proximity matter? Land Use Policy 24, 296-305.

Saz, S.D., García-Menéndez, L., 2003. The nonmarket benefits of redeveloping dockland areas for recreational purposes: the case of Castellón, Spain. Environ. Plan. A 35, 2115-2129.

Sherer, P.M., 2006. The Benefits of Urban Parks. Why America Needs More City Parks and Open Space. The Trust for Public Land, San Francisco. 
Smith, V.K., 2006. Fifty years of contingent valuation. In: Alberini, A., Khan, J.R. (Eds.), Handbook on Contingent Valuation. Edward Elgar, Cheltenham, UK, pp. 7-65.

Stumborg, B.E., Baerenklau, K.A., Bishop, R.C., 2001. Nonpoint source pollution and present values: a contingent valuation study of Lake Mendota. Rev. Agric. Econ. 23, 120-132.

Tajima, K., 2003. New estimates of the demand for urban green space: implications for valuing the environmental benefits of Boston's big dig project. J. Urban Affairs 25, 641-655.

Tobin, J., 1958. Estimation of relationships for limits dependent variables Econometrica 26, 24-36.

Tyrväinen, L., 1997. The amenity value of the urban forest: an application of the hedonic pricing method. Land. Urban Plan. 37, 211-222.

Tyrväinen, L., Mäkinen, K., Schipperijn, J., 2007. Tools for mapping social values of urban woodlands and other green areas. Land. Urban Plan. 79, 5-19.

Tyrväinen, L., Meittinen, A., 2000. Property prices and urban forest amenities. J. Environ. Econ. Manage. 39, 205-233.

Tyrväinen, L., Väänänen, H., 1998. The economic value of urban forest amenities: and application of the contingent valuation method. Land. Urban Plan. $43,105-118$.
UNFPA, 2005. State of World Population 2005. United Nations Population Fund. Veall, M.R., Zimmermann, K.F., 1992. Pseudo- ${ }^{2}$ 's in the ordinal probit model. J. Math. Soc. 16, 333-342.

Walker, C., 2004. The Public Value of Urban Parks. The Urban Institute, Washington.

Weitzman, M.L., 1998. Why the far-distant future should be discounted at its lowest possible rate. J. Environ. Econ. Manage. 36, 201-208.

Weitzman, M.L., 2001. Gamma discounting. Am. Econ. Rev. 91, 260-271.

Whitehead, J.C., 2006. A practitioner's primer on the contingent valuation method. In: Alberini, A., Khan, J.R. (Eds.), Handbook on Contingent Valuation. Edward Elgar, Cheltenham, UK, pp. 66-91.

Whitehead, J.C., Hoban, T.J., Clifford, W.B., 1995. Measurement issues with iterated, continuous/interval contingent valuation data. J. Environ. Manage. $43,129-139$

Willis, K.G., 2003. Pricing public parks. J. Environ. Plan. Manage. 46, 317.

Wilson, E.O., 1993. Biophilia and the conservation ethic. In: Keller, S.R., Wilson, E.O. (Eds.), The Biophilia Hypothesis. Island Press, Washington, DC.

Yoo, S.-H., Kwak, S.-J., Kim, T.-Y., 2000. Dealing with zero response data in contingent valuation surveys: application of least absolute deviations estimator. Appl. Econ. Lett. 7, 181-184. 